\title{
Mentoring each other \\ Creating a community of practice for aspiring and current library managers
}

I: ntegrating formal management training into library school curriculum has been a topic of discussion for years, with varying progress. And in our experience, librarians are rarely given formal training on the job before becoming managers. We need to find ways to support new managers, helping them to acquire skills to handle the interpersonal, economic, and political challenges. Human Resources departments can provide valuable training in policy and procedures of the organization, but libraries have unique management challenges that may not exist elsewhere on campus. Librarians may be asked to manage faculty, staff, and student workers. They may need to arrange for coverage for service points, as well as work as an academic department. They work on projects with people from all parts of campus. Sometimes only other librarians understand the different dynamics of our situation. But when you're a manager, it can be awkward to discuss specific management concerns with colleagues in your organization. Meeting with librarians from other institutions provides a comfortable level of anonymity.

Our project started, as so many do, over coffee. In 2017, Candice Benjes-Small and Katelyn Burton had met to discuss Burton's new position at Virginia Western Community College, and the conversation turned to management issues. Burton was new to management, while Benjes-Small had over a decade of experience, and both felt like they could benefit from a friendly ear to brainstorm problems, concerns, and solutions. At that point in time, they worked 45 miles apart — close enough for an occasional face-toface chat but too far for anything more frequent. But there was this new program called Zoom that our universities had recently licensed. Maybe that could help facilitate such meetings? From this initial coffee conversation, the idea to start a small management community of practice that would meet online was born. Our community of practice grew to include participants who aspired to become managers, those who were new to a management role, and those with many years of management experience.

\section{What is a community of practice?}

Librarianship is full of communities of practice. We may not be consciously aware of them, but they exist, nonetheless. "Communities of practice are groups of people who share a concern, a set of problems, or a passion about a topic, and who deepen their knowledge and expertise in this area by interacting on an ongoing basis." "They help us to solve problems with assistance from members of our profession who have had similar experiences or are going through similar situations by offering us new perspectives on our issues, and the support to solve

Alyssa Archer is coordinator of faculty outreach and instruction librarian at Radford University, email: aarcher2@radford.edu, Candice Benjes-Small is head of research services at William \& Mary, email: cbsmall@ wm.edu, Katelyn Burton is reference and instruction librarian and acting coordinator of the Academic Link at Virginia Western Community College, email: kburton@ virginiawestern.edu, Jennifer Resor-Whicker is interim head of research services at Radford University, email: jrwhicker@radford.edu, and Rebecca Seipp is assistant university librarian at Hollins University, email: seipprl@ hollins.edu

(c) 2021 Alyssa Archer, Candice Benjes-Small, Katelyn Burton, Jennifer Resor-Whicker, and Rebecca Seipp 
the problems we face. They allow us to explore and learn together. Communities of practice do not have to be limited to one institution and can be spread out to include individuals from many different types of institutions.

According to Etienne Wenger, Richard McDermott, and William M. Snyder, interactions in a community of practice are structured and centered around a specific goal that the group agrees on. The group discusses and explores problems based on an agreement about the general topic. This allows the group to build trust and feel comfortable with sharing knowledge and experiences in this area. It gives the group access to expertise that may not have been available otherwise. The group builds a knowledge base that belongs to them. If documented correctly, this knowledge will be available to share beyond the community of practice. The presence of this knowledge is what makes the community of practice successful.

\section{How does our group reflect community of practice standards?}

While our group members did not research communities of practice before starting, the experience of this group has mirrored the criteria above. These components can also be broken down into three overlapping segments: community, domain, and practice. $^{2}$

The members of this community have preexisting relationships that formed outside of this group, from either working at the same institution at different times or through regional structures centered around library instruction. This helped build the necessary trust to handle difficult conversations, but this community of practice solidified around our intentional and regular meetings to discuss library management issues.

Domain usually applies to a shared competence but may also apply to shared interest: while one of our group members does not yet have a supervisory role in a library, the members with longer experience in library management help to provide a backbone of expertise and perspective during exercises. The members in newer managerial roles help firsthand to illustrate aspects of the sometimes difficult transition from worker to management, and bring vital information to the group.

The practice that builds during our meetings, as the literature discusses, is the set of shared stories that we develop over time that change our behavior outside of the group. Our meetings have had a positive impact on how we each handle work scenarios, whether it's better communication with a direct report, discussing conflict with a supervisor, advocating for a plan of action, or in managing a project.

\section{Logistics of our community of practice}

We meet monthly over Zoom for an hour. Since 2017, our membership of core members has ranged from five-to-eight people. We begin with a guest speaker, who is a librarian from outside our community with management experience. Through the years, we have invited librarians we know through our professional connections. At first, Benjes-Small's network was heavily called upon but in more recent times, other members have invited speakers they knew. Ahead of the meeting, the guest speaker is asked to provide a brief "management autobiography," and plan to share a case study that taught the guest speaker an important manager lesson. These case studies are anonymized, and confidentiality all-around is promised. During our meeting, the guest speaker presents the case study, stopping short of saying how the situation was resolved. The community of practice members then debate what they would do as the manager in the situation, asking the speaker for further information, as needed. At the conclusion, the speaker then shares what happened in real life. This usually takes about half an hour. The remaining time is spent either discussing another case study (we used a lot of letters from the "Ask A Manager" blog) or throwing out our own management dilemmas and using the group as a brain trust.

\section{Participant feedback}

Three years into our monthly meetings, the most valuable outcome has been the chance to pause and reflect on management issues. Since our group formed, three participants have been promoted into management positions or had their position descriptions change radically. In the midst of many personal/personnel changes, a global pandemic, a shift to remote work and online instruction, and myriad other challenges, carving out time for deep reflection has seemed impossible. The rhythm of a monthly discussion provides treasured time, space, and encouragement to focus on management. 
Additionally, this community of practice has led to connections across our region and field. Having the chance to "meet" other managers and build professional contacts has led to a network of collaborators and mentors. We've heard from managers who faced many challenges and learned from their experiences, but we also built a support system, in case we should face similar issues in our workplaces. This has helped the participants feel more confident and better prepared to face the difficult conversations that management requires.

\section{Guest speaker feedback}

We asked our guest speakers to reflect on their experiences as the "outside" voice for our community of practice. A number of common themes emerged in the responses. Many appreciated the need for such a group to exist, pointing out that librarians rarely get a solid management foundation in library school. We are often promoted because we excel at the contributor level, not because we possess innate management skills, and management work can be very isolating and lonely.

Guests valued the different viewpoints that our community provided. As mentioned, the speaker shares a real-life scenario with us. In the reflections, guests said the resulting conversations gave them an opportunity to consider new perspectives on these situations. They also liked that the discussions drove home that there is rarely one "right" answer to management concerns.

Finally, guest speakers expressed a desire to belong to a similar group. They complimented the supportive nature of our community; the opportunity to have intentional, thoughtful conversations about management; and the space to have confidential discussions. "Overall, I thought this was an excellent program, which I would have greatly enjoyed participating in during an earlier stage of my career," wrote one.

\section{Starting your own community}

So where does this leave you? Whether you're an aspiring manager or you're already leading a team of people, we encourage you to reach out to your trusted network to get your own management mentoring group started. Here are a few important elements to building your own group:

- Confidentiality is required for this group to be successful. Whether you're inviting guests who will share real management dilemmas, or your fellow member would like to dive into a current problem, it's imperative for everything to stay within the group. This allows for productive conversations and honest feedback.

- Who are your people? Who is in your extended library network that you trust? Reach out to those people to start this group. While everyone doesn't need to be from a different institution, it's helpful to have people from different organizations because it diversifies the experiences in the group. Regardless of who you invite, trust is a crucial element because confidentiality is so important.

- Facilitation is a real and important job in the group. The meeting facilitator sets the agenda, prepares any guests (see below) or readings, is ready to ask questions, and keeps track of time. Recognize that these elements are important to a productive meeting and share the facilitation responsibilities.

- Prepare any meeting guests by letting them know the format of your meetings. They should know how much time they have to present their problem, when to pause for group questions, and when they should share how they handled the problem.

- Remember that this group is a democracy, and no single person is bequeathing their management wisdom on others. As a community of practice, you're learning together and setting the trajectory of the group together.

- Examine the makeup of your group with an eye towards blind spots and biases. Our group consists largely of White women in a field composed overwhelmingly of the same. We encourage you to look at the makeup of your community of practice, who you invite as guests, and the topics which you discuss with a critical lens. Think intentionally about equity and inclusion.

\section{Conclusion}

Our community of practice has provided opportunities to learn, to network, and to grow as professionals. During the pandemic, we found this group to be incredibly beneficial because never did library management feel lonelier than during a lockdown. By continuing with our monthly meetings over Zoom, we forged even tighter con-

(continues on page 484) 
promotion criteria, effects of increasing adjunctification on the futures of disciplines themselves, and other disciplinary boundaries that-while often invisible—are always constitutive.

\section{Acknowledgement}

Many thanks to Susan Garfinkel at the Library of Congress for assistance in tracing the history of the "Digital Humanities" Library of Congress Subject Heading.

\section{Notes}

1. Andrea Baer, "Critical Information Literacy in the College Classroom: Exploring Scholarly Knowledge Production through the Digital Humanities," in Information Literacy and Social Justice: Radical Professional Praxis, ed. Lua Gregory and Shana Higgins, (Los Angeles: Library Juice Press, 2013), 109.

2. Richard Grusin, "The Dark Side of Digital Humanities: Dispatches from Two Recent MLA Conventions," differences 25, no. 1 (May 1, 2014): 87, https://doi.org/10.1215 /10407391-2420009.

3. Claire Warwick, “'They Also Serve': What DH Might Learn about Controversy and Service from Disciplinary Analogies," in Debates in the Digital Humanities 2019, ed. Matthew K. Gold and Lauren F. Klein (Minneapolis: University of Minnesota Press, 2019), https://dhdebates. gc.cuny.edu/projects/debates-in-the-digital -humanities-2019.

4. Gold and Klein, "Introduction: A DH That Matters," in Debates 2019.

5. A genealogy of the LCSH-est. 2008would be a fascinating undertaking. For this essay's purposes its absence from DH literature suffices.

6. "DHQ: Digital Humanities Quarterly: About," accessed April 9, 2021, http://digitalhumanities.org: $8081 /$ dhq /about/about.html.

7. Melissa Terras and Julianne Nyhan, "Father Busa's Female Punch Card Operatives," in Debates in the Digital Humanities 2016, ed. Gold and Klein (Minneapolis: University of Minnesota Press, 2016), https://dhdebates.gc.cuny.edu/read /untitled/section/ 1 e 57217 b-f262-4f25 -806b-4fcf1548beb5.

8. Melissa Adler, Cruising the Library: Perversities in the Organization of Knowledge (New York: Fordham University Press, 2017), 2.

9. Charles Cutter, Rules for a Dictionary Catalog, U.S. Government Printing Office, 1904.

10. Michel Foucault, Society Must Be Defended: Lectures at the Collège de France, 1975-76, ed. Mauro Bertani and Alessandro Fontana, trans. David Macey (New York: Picador, 2003), 2, qtd. in Adler, 23.

11. Christina Sharpe, In the Wake: On Blackness and Being (Durham: Duke University Press, 2016), 13.

12. Ronjaunee Chatterjee, Alicia Mireles Christoff, and Amy R. Wong, "Undisciplining Victorian Studies," Los Angeles Review of Books, July 10, 2020, https://lareviewofbooks.org /article/undisciplining-victorian-studies/.

13. Lincoln Mullen, "Digital Humanities Is a Spectrum; or, We're All Digital Humanists Now," April 29, 2010, https://lincolnmullen. $\mathrm{com} / \mathrm{blog} /$ digital-humanities-is-a-spectrum-or -we8217re-all-digital-humanists-now/. ュ

("Mentoring each other," continued from page 476)

nections and reinforced trust among the group members. Whether we are exploring new ideas, struggling with current challenges, or bouncing new ideas off each other, we always find our time together to be well spent. We hope you can find a similar community that will help you thrive.

\section{Notes}

1. Etienne Wenger, Richard McDermott, and
William M. Snyder, Cultivating communities of practice: A guide to managing knowledge (Boston, Mass: Harvard School Press, 2002), 9.

2. Etienne Wenger-Trayner and Beverly WengerTrayner, "Introduction to communities of practice: A brief overview of the concept and its uses," WengerTrayner, https://wenger-trayner.com/introductionto-communities-of-practice/ (accessed May 28, 2021). 